\title{
Overexpression of p21 Has Inhibitory Effect on Human Hematopoiesis by Blocking Generation of CD43 + Cells via Cell-Cycle Regulation
}

\author{
Jiahui Zeng ${ }^{1}$, Huifang Zhang ${ }^{1}$, Yuanling Liu ${ }^{1}$, Wencui Sun ${ }^{1}$, Danying $\mathrm{Yi}^{1}$, Lijiao Zhu ${ }^{1}$, \\ Yonggang Zhang ${ }^{1}$, Xu Pan ${ }^{1}$, Yijing Chen ${ }^{1}$, Ya Zhou ${ }^{1}$, Guohui Bian ${ }^{1}$, Mowen Lai ${ }^{1}$, \\ Qiongxiu Zhou ${ }^{1}$, Jiaxin Liu ${ }^{1}$, Bo Chen ${ }^{1}$, Feng $\mathrm{Ma}^{1,2,3}$ \\ ${ }^{1}$ Research Center for Stem Cell Therapies, Institute of Blood Transfusion, \\ Chinese Academy of Medical Sciences \& Peking Union Medical College (CAMS \& PUMC), Chengdu, China \\ ${ }^{2}$ State Key Laboratory of Biotherapy, Sichuan University, Chengdu, China \\ ${ }^{3}$ State Key Laboratory of Experimental Hematology, CAMS \& PUMC, Tianjin, China
}

Background and Objectives: p21, an important member of the Cip/Kip family, is involved in inhibitory effects of RUNXIb overexpression during the early stage of human hematopoiesis.

Methods and Results: We established a human embryonic stem cell (hESC) line with inducible expression of p21 (p21/hESCs). Overexpression of p21 did not influence either mesoderm induction or emergence of CD34+ cells, but it significantly decreased the production of $\mathrm{CD} 43+$ cells and changed the expression profile of hematopoiesis-related factors, leading to the negative effects of p21 on hematopoiesis.

Conclusions: In RUNXIb/hESC co-cultures when RUNXIb was induced from D0, perturbation of the cell cycle caused by upregulation of p21 probably prevented the appearance of $\mathrm{CD} 43+$ cells, but not $\mathrm{CD} 34+$ cells. The mechanisms via which $\mathrm{CD} 34+$ cells are blocked by $R U N X 1 b$ overexpression remain to be elucidated.

Keywords: p21, RUNX1, CD43, Hematopoiesis, hPSC, AGM-S3, Inducible expression, PiggyBac, Cell cycle

Received: March 3, 2020, Revised: March 7, 2020,

Accepted: May 15, 2020, Published online: June 30, 2020

Correspondence to Bo Chen

Research Center for Stem Cell Therapies, Institute of Blood Transfusion, Chinese Academy of Medical Sciences \& Peking Union Medical College (CAMS \& PUMC), No.26, Huacai Road, Chenghua District, Chengdu, Sichuan 610052, China

Tel: +86-28-61648515, Fax: +86-28-61648515

E-mail: Bo_Chen@ibt.pumc.edu.cn

Co-Correspondence to Feng $\mathrm{Ma}$

Research Center for Stem Cell Therapies, Institute of Blood Transfusion, Chinese Academy of Medical Sciences \& Peking Union Medical College (CAMS \& PUMC), No.26, Huacai Road, Chenghua District, Chengdu, Sichuan 610052, China

Tel: +86-28-61648510, Fax: +86-28-61648510

E-mail: mafeng@ibt.pumc.edu.cn

(a) This is an open-access article distributed under the terms of the Creative Commons Attribution Non-Commercial License (http://creativecommons.org/ licenses/by-nc/4.0/), which permits unrestricted non-commercial use, distribution, and reproduction in any medium, provided the original work is properly cited.

Copyright (c) 2020 by the Korean Society for Stem Cell Research

\section{Introduction}

Hematopoiesis can be divided into primitive hematopoiesis starting from the yolk sac (YS) (1) and adult hematopoiesis originating from aorta-gonad-mesonephros (AGM) region (2). The study of hematopoietic mechanisms is important for understanding human hematopoietic processes and related clinical applications (3). Human embryonic stem cell (hESC) culture technology and adult cell reprogramming technology enables production of human pluripotent stem cells, including human embryonic stem cells (hESC) and human induced pluripotent stem cells (hiPSC). Both types of cells have become important as initial sources of material for in vitro culture systems (4-6), which can generate large numbers of red blood cells and other types of blood cells from hESCs/hiPSCs (7-9). They 
also provide good models for studying the molecular regulatory mechanisms involved in hematopoietic differentiation. Previously, we showed that RUNXIb overexpression at the early stage severely impedes hematopoiesis, and that this effect was partially rescued by RepSox, an inhibitor of the TGF- $\beta$ signaling pathway (10). Subsequent transcriptional profiling analysis revealed that many members of the cyclin-dependent kinase inhibitor (CKI) family, including p21 (encoded by $C D K N 1 A$ ), are involved in mediating these effects of RUNXIb.

The CKIs include two families: the Cip/Kip family [including $\mathrm{p} 21^{\mathrm{Cipl} / \mathrm{Waf} 1 / \mathrm{Sdil}}(\mathrm{p} 21), \mathrm{p} 27^{\mathrm{Kip} 1}$ (p27), and p57 ${ }^{\mathrm{Kip} 2}$ (p57)], and the INK4 family [including $\mathrm{p} 16^{\mathrm{INK} 4 \mathrm{a}}(\mathrm{p} 16)$, p15 ${ }^{\mathrm{INK} 4 \mathrm{~b}}$ (p15), p18 ${ }^{\mathrm{INK} 4 \mathrm{c}}$ (p18), and p19 ${ }^{\mathrm{INK} 4 \mathrm{~d}}$ (p19)] (11). As an important member of the Cip/Kip family, p21 (also known as CDK-interacting protein 1) is activated under special conditions, such as DNA damage or hypoxia, and is involved in cell differentiation, senescence, and apoptosis (12). Expression of CDKN1A (p21) plays an important role in hematopoietic stem cell quiescence, in vitro expansion (13), and megakaryocyte differentiation (14). Our research showed that $\mathrm{p} 21$ is also involved in the inhibitory effects of RUNXIb on hematopoiesis. Because the AGM region provides the key microenvironment for adult hematopoiesis during development, mouse AGM-S3 stromal cells can also mimic the adult hematopoietic microenvironment for hESC-originated hematopoiesis to some extent (10, 15-17). We used an inducible expression system based on the piggyBac transposon to characterize accurately the role of p21 in human hematopoiesis in the hESC/AGM-S3 co-culture system, and to explore its contribution to inhibition of hematopoiesis by RUNXIb.

\section{Materials and Methods}

\section{RUNX1b/hESC co-cultures with AGM-S3 cells}

The $R U N X 1 b / \mathrm{hESC}$ had been established using the PB-Tet-on-GFP-T2A-hRUNX1b vector, as described previously (10). RepSox is an inhibitor of the TGF- $\beta$ signaling pathway, and $0.33 \mu \mathrm{M}$ RepSox was proved to be optimal to rescue the blockage effects of RUNXIb on hematopoiesis, which detail information could be seen in Chen et al. (10). RUNXIb/hESC co-cultures (with AGM-S3 cells) were treated with only DOX or with both DOX and 0.33 $\mu \mathrm{M}$ RepSox from D0, and then cell cycle analyses, qRT-PCR, and western blotting were performed at D4. Untreated D4 RUNX1b/hESC co-cultures were used as negative controls.

\section{Establishment of a p21-inducible hESC line}

The coding sequence (CDS) of p21 (CDKN1A) was synthesized and cloned into pUC57. After double digestion with SnaBI and EcoRI, the CDS was inserted between the SwaI and EcoRI sites of PB-Tet-on-OE to yield the PiggyBac-based Tet-on inducible expression vector PB-Tet-on-GFP-T2A-hp21. H1 hESCs (provided by Prof. Tao Cheng) were co-transfected with this vector and the helper plasmid pB200PA-1 using Lipofectamine 3000 (Invitrogen, USA), selected with $1 \mu \mathrm{g} / \mathrm{ml}$ puromycin, and passaged using ReleSR (STEMCELL Technologies) to establish the p21-inducible hESC line (p21/hESCs). qRTPCR and western blotting analyses confirmed the efficiency and stringency of inducible overexpression of $\mathrm{p} 21$. Pluripotency was confirmed by western blotting for OCT4, SOX2, and NANOG in cells treated with or without doxycycline (DOX). The primers and antibodies used for these tests are listed in Supplementary Materials and Methods, Table S1 and Table S2.

\section{Co-culture of hESCs with AGM-S3 stromal cells}

hESCs were induced to undergo hematopoietic differentiation by co-culture with the mouse stromal cell-derived line AGM-S3, as reported previously (18). hESCs were cut into small squares containing $0.25 \sim 0.5 \times 10^{3}$ cells, plated onto irradiated AGM-S3 cells in hPSC maintenance medium, cultured for another 3 days at $37^{\circ} \mathrm{C}$ in $5 \% \quad \mathrm{CO}_{2}$, and then switched to hematopoiesis-inducing medium $(10,18)$. The day of the media switch was defined as day 0 (D0). Subsequently, the culture medium was replaced every day. At the indicated times, co-cultures were dissociated using $0.05 \sim 0.25 \%$ trypsin/EDTA (Invitrogen) and subjected to further analysis.

\section{Cell sorting and further hematopoiesis culture}

Non-induced or induced $\mathrm{p} 21 / \mathrm{hESC}$ co-cultures at D2 were dissociated by treatment with $0.05 \%$ trypsin and stained with anti-KDR/7-AAD antibody. KDR + cells were sorted using a BD FACSJazz Cell Sorter, and their purity was confirmed by FACS. About $5 \times 10^{3}$ sorted cells were re-plated in 24-well plates on irradiated AGM-S3 for 8 days with or without DOX induction; hematopoiesis-inducing medium was replaced every other day. At the indicated times, the cells were subjected to FACS analysis.

\section{Cell-cycle analysis}

Non-induced or D0-induced $\mathrm{p} 21 / \mathrm{hESC}$ co-cultures at D4 or D6, and D4 co-cultures of RUNX1b/hESC treated with or without DOX, or with DOX and RepSox together from D0, were further incubated with $10 \mu \mathrm{M}$ BrdU for 
$12 \mathrm{~h}$, dissociated by treatment with $0.05 \%$ trypsin, stained with anti-KDR antibody (at D4) or anti-CD34 antibody (at D6), and then subjected to analysis of cell-cycle status using the APC-BrdU Flow Kit (BD Biosciences), which was visualized by FACS.

\section{Hematopoietic colony-forming assay}

Hematopoietic colony-forming assays of co-cultured cells were performed as described previously (16). Briefly, D12 co-cultured cells were dissociated with $0.25 \%$ tryp$\sin /$ EDTA. Thereafter, $5 \times 10^{4}$ co-cultured cells were added to $80 \%$ MethoCult H4230 (STEMCELL Technologies) containing $100 \mathrm{ng} / \mathrm{ml}$ stem cell factor (SCF), $100 \mathrm{ng} / \mathrm{ml}$ interleukin-6 (IL-6), $10 \mathrm{ng} / \mathrm{ml}$ interleukin-3 (IL-3), $10 \mathrm{ng} / \mathrm{ml}$ Fms-related Tyrosine Kinase 3 Ligand (FL), $10 \mathrm{ng} / \mathrm{ml}$ thrombopoietin (TPO), $10 \mathrm{ng} / \mathrm{ml}$ granulocyte-macrophage colony-stimulating factor (GM-CSF), and 4 units/ml erythropoietin (EPO), and then were incubated in $5 \% \mathrm{CO}_{2}$ at $37^{\circ} \mathrm{C}$ for 14 days. Colony-forming units-erythroid
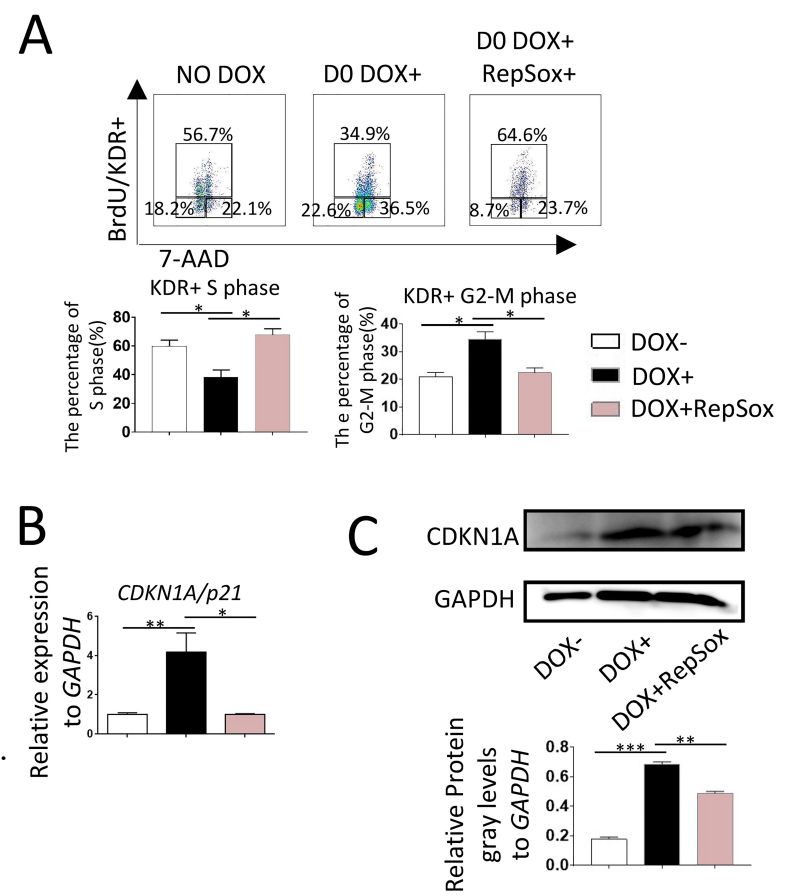

Fig. 1. $\mathrm{p} 21$ is involved in inhibitory effects of $R U N X 1 b$ on the mesoderm-hemogenesis transition. D0-induced RUNX1b/hESC co-cultures with AGM-S3 cells at D4, (A) Cell-cycle analyses revealed that the proportion of cells in $\mathrm{S}$ phase dropped significantly when RUNX1b was overexpressed from D0, and that these inhibitory effects could be partially rescued by RepSox. (B, C) qRT-PCR and western blotting analysis showed that p21 was upregulated when DOX was added from D0, and that this effect could be counteracted by $0.33 \mu \mathrm{M}$ RepSox. Grayscale scanning analyses were performed using Gel-Pro Analyzer 4.
(CFU-E) was calculated at $7 \sim 10$ days, whereas burstforming units-erythroid (BFU-E), colony-forming unitsmixed (CFU-Mix), and colony-forming units-granulocyte/ macrophage (CFU-GM) were calculated at 12 14 days, as previously described (17).

\section{May-Grunwald-Giemsa (MGG) staining}

Cells in BFU-E colonies were harvested and spun onto glass slides using a Cytospin 4 Cytocentrifuge (Thermo Fisher Scientific). For morphological observation, cells were stained with May-Grunwald-Giemsa solution (MERCK) and imaged using an Olympus BX53 microscope equipped with an oil objective.

\section{Results}

Overexpression of $R U N X 1 b$ upregulates $\mathrm{p} 21$ and decreases the proportion of $\mathbf{S}$-phase cells in a TGF- $\beta$-dependent manner

In co-cultures with AGM-S3 cells, overexpression of $R U N X 1 b / c$ in hESCs at the early stage can block the mesoderm-hemogenesis transition, and treatment with $0.33 \mu \mathrm{M}$ RepSox can alleviate partially this blockage (10). Cell-cy-
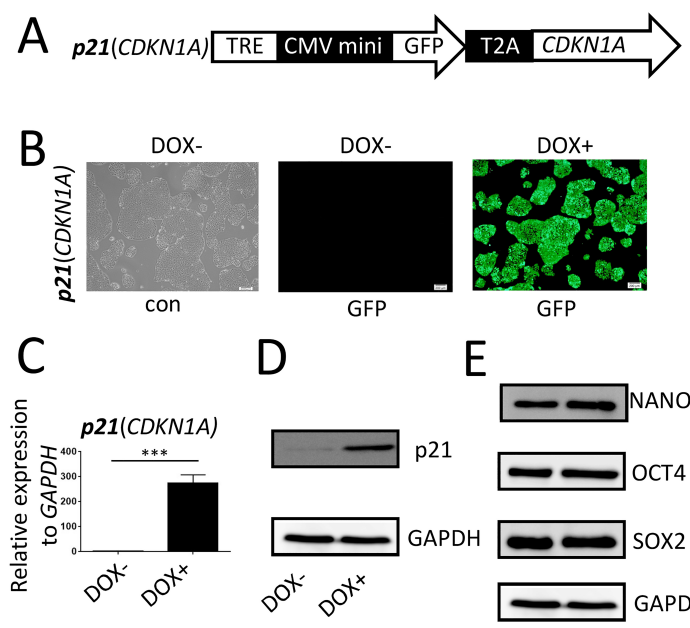

E

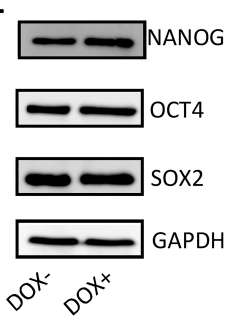

Fig. 2. Construction and confirmation of inducible p21/hESC lines. (A) Schematic representation of the PiggyBac constructs used to inducibly express p21. TRE, tet-on regulation element; CMV mini, cytomegalovirus minimum promoter; $\mathrm{T} 2 \mathrm{~A}$, Thosea asigna virus $2 \mathrm{~A}$ peptide. (B) After p21/hESCs were induced for $48 \mathrm{~h}$, the cells were imaged by fluorescence microscopy to observe co-expression of GFP. (C, D) qRT-PCR and western blotting were used to confirm that inducible expression of p21 was highly stringent and efficient at the transcriptional and protein levels. (E) Pluripotency of p21/ hESCs (non-induced or induced) was confirmed by western blotting for SOX2, OCT4, and NANOG. 
cle analysis of D0-induced RUNX1b/hESC co-cultures at D4 revealed that the proportion of $\mathrm{KDR}+$ cells in $\mathrm{S}$ phase was significantly lower than in non-induced controls (Fig. 1A). qRT-PCR (Fig. 1B) and western blotting (Fig. 1C) at $\mathrm{D} 4$ revealed that expression of $\mathrm{p} 21$ was upregulated in D0-induced RUNX1b/hESCs. All of these effects could be counteracted by $0.33 \mu \mathrm{M}$ RepSox. These results indicated that the inhibitory effects of RUNXIb on hematopoiesis might be closely related to the expression level of p21 and changes in cell-cycle status.

\section{A FACS analyses at D6

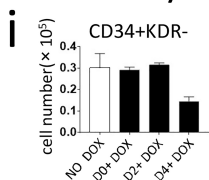 \\ i. 需 $0.5 \mathrm{CD} 34+\mathrm{CD} 43-$ \\ ii
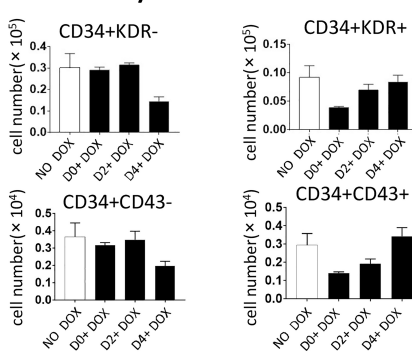 \\ B FACS analyses at D12
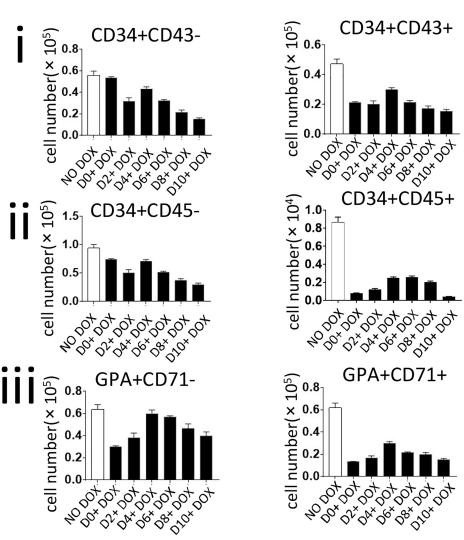 \\ (1.0, CD $34+C D 45+$
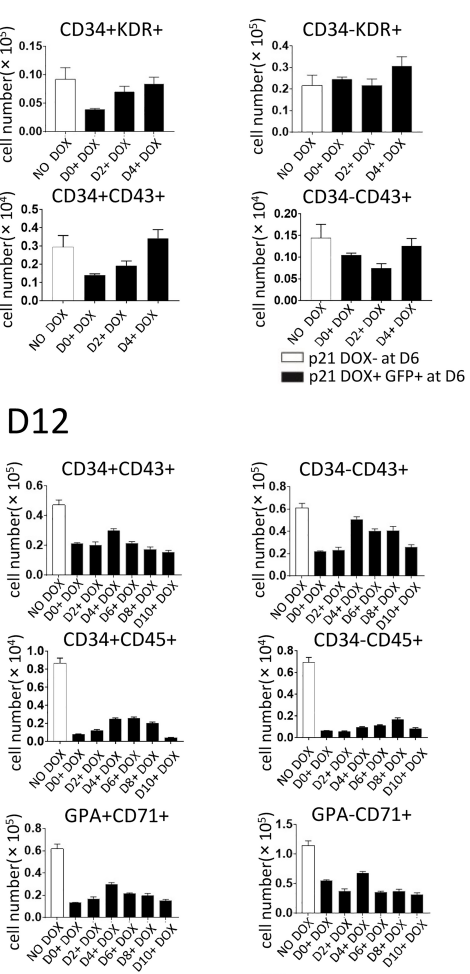 \\ $\square$ p21 DOX-at D6

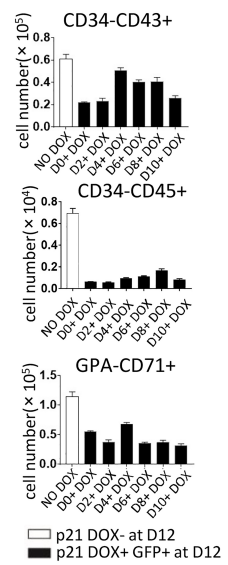

Fig. 3. Overexpression of p21 blocks hematopoiesis in co-culture with AGM-S3 cells. p21/hESC co-cultures with AGM-S3 cells were treated with DOX from D0, D2, D4, D6, D8, or D10, and then subjected to FACS with antibodies against CD34/KDR and CD34/CD43 (at D6) or GPA/CD71, CD34/CD43, and CD34/CD45 (at D12) to compare non-induced co-cultures and the GFP+ fraction of co-cultures treated with DOX. (A) When p21 was overexpressed from the early stage, the abundance of D34+KDR - and CD34+CD43 - cells was not influenced at D6, whereas the emergence of $\mathrm{CD} 34+\mathrm{KDR}+$ and $\mathrm{CD} 34+\mathrm{CD} 43+$ cells was significantly blocked. (B) Most hematopoietic populations, such as CD34-CD43+, CD34+CD43+, CD34+CD45+, CD34-CD45+, and GPA $+\mathrm{CD} 71+$, dramatically decreased at D12, regardless of when induction of p21 started. This observation indicates that p21 has strong negative effects on hematopoietic cells $(\mathrm{CD} 43+)$ but not their endothelial precursors $(\mathrm{CD} 34+)$.

\section{p21/hESCs exhibit inducible p21 overexpression and normal pluripotency}

The p21/hESC line (Fig. 2A) was treated with DOX for $48 \mathrm{hr}$. Fluorescence microscopy, quantitative reverse transcription PCR (qRT-PCR), and western blot analyses confirmed that p21 overexpression was efficiently induced and under stringent control (Fig. 2B D). Western blot analyses revealed that the stemness-specific markers, OCT4, SOX2, and NANOG, were expressed normally in p21/hESCs irrespective of DOX treatment (Fig. 1E), confirming that these cells had normal pluripotency.

\section{Overexpression of p2l at the early stage blocks hematopoiesis}

The effects of p21 overexpression on hematopoiesis differed according to the day on which DOX treatment was initiated. FACS analyses of co-cultures of p21/hESCs and AGM-S3 cells at D6 revealed that treatment with DOX starting on D0 did not influence the production of CD34+ $\mathrm{KDR}-$, CD34-KDR +, or CD34+CD43- cells, but severely decreased the production of $\mathrm{CD} 34+\mathrm{KDR}+$ and CD34+CD43 + cells. By contrast, these effects were attenuated or even abolished when DOX treatment was initiated after D4 (Fig. 3A, Supplementary Fig. S1A). Genera-

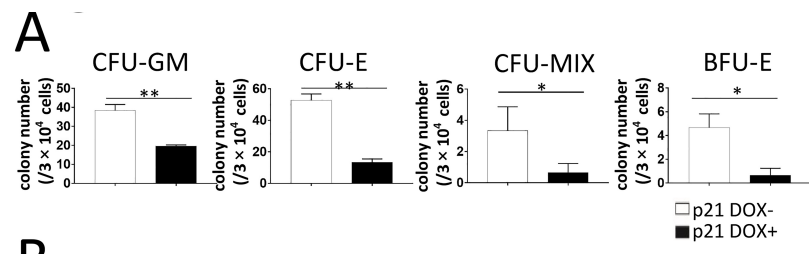

B

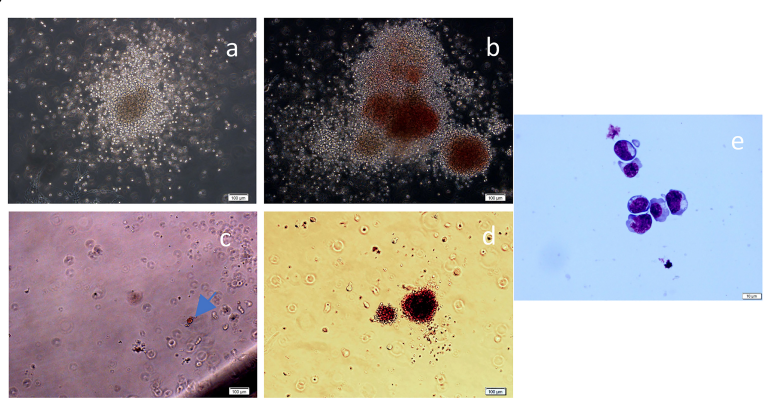

Fig. 4. Colony assays confirmed the inhibitory effects of p21 on hematopoiesis. D0-induced or non-induced co-cultures of p21/ hESCs with AGM-S3 (about $3 \times 10^{4}$ cells) at D12 were subjected to colony culture assays to assess their hematopoietic potentials. (A) The number of each type of colony derived from $3 \times 10^{4}$ co-cultured cells. $\mathrm{p}<0.05$ was considered significant. (B) Typical morphologies of CFU-Mix (a), CFU-E (b), BFU-E (c), and CFU-GM (d) colonies. Scale bar, $100 \mu \mathrm{m}$. MGG staining of cells in BFU-E colonies (e). Scale bar, $10 \mu \mathrm{m}$. The hematopoietic potential of p21-induced co-cultures dropped significantly. 
tion of $\mathrm{CD} 34+\mathrm{KDR}+$ and $\mathrm{CD} 34+\mathrm{CD} 43+$ cells at D6 was negatively influenced by induction of p21 overexpression from an early stage, especially from D0. In addition, production of hematopoietic progenitor cells $(\mathrm{CD} 34+\mathrm{CD} 45+)$ and erythroid progenitor cells (GPA+ $\mathrm{CD} 71+)$ at D12 were dramatically reduced regardless of when induction of $\mathrm{p} 21$ was initiated. These results indicate that hematopoiesis was broadly blocked by $\mathrm{p} 21$ induction (Fig. 3B, Supplementary Fig. S1B).

\section{Overexpression of p2l blocks colony formation}

To further confirm that overexpression of p21 had negative effects in hematopoiesis, we performed hematopoietic colony assays on co-cultures at D12. D0-induced p21 overexpression significantly blocked formation of CFU-GM, CFU-E, CFU-Mix, and BFU-E colonies (Fig. $4 \mathrm{~A}$ ), and this inhibitory effect was consistent with the results of FACS analyses (Fig. 3B, Supplementary Fig. S1). The morphologies of typical hematopoietic colonies were examined by phase-contrast microscopy (Fig. 4B, panel a $\sim$ d). BFU-E cells were confirmed by May-GrunwaldGiemsa staining (MGG) (Fig. 4B, panel e).
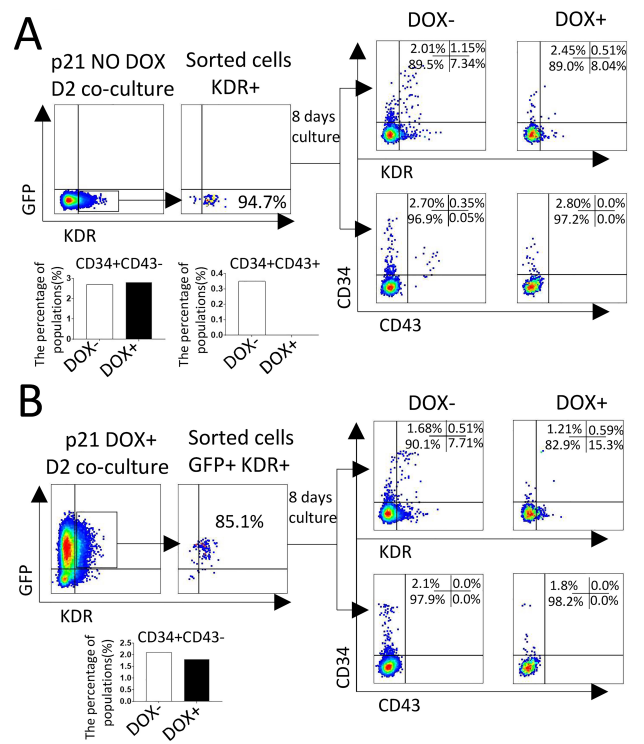

Fig. 5. Induction of p21 from the early stage severely blocked the emergence of CD43+ cells. KDR+ or GFP+KDR + cells sorted from D0-induced or non-induced p21/hESC co-cultures at D2. About $5 \times 103$ cells were re-plated on irradiated AGM-S3 in 24-well plates or further hematopoietic culture, treated with or without DOX for 8 days, and then subjected to FACS analysis using a combination of CD34/KDR or CD34/CD43 antibodies. The results indicated that induction of $\mathrm{p} 21$ from D0 or D2 significantly blocked the appearance of CD43 + cells, but not CD34+ cells.

\section{Overexpression of p21 from the early stage blocks generation of $\mathrm{CD} 43+$ cells but not CD34 + cells}

At D2, KDR + cells were sorted from co-cultures of D0-induced or non-induced p21/hESC with AGM-S3, and then re-plated on irradiated AGM-S3 for further hematopoietic culture with or without DOX (designated D++, $\mathrm{D}+-, \mathrm{D}-+$, and $\mathrm{D}--)$. FACS analyses revealed that when $\mathrm{p} 21$ overexpression was induced from D0 or D2, production of $\mathrm{CD} 34+\mathrm{KDR}+$ cells dropped significantly $(\mathrm{D}-+$ vs. $\mathrm{D}--)$, and production of $\mathrm{CD} 34+\mathrm{CD} 43+$ and CD34-CD43+ cells was completely blocked (Fig. $5 \mathrm{~B})$. These results indicate that ectopic expression of $\mathrm{p} 21$ from the early stage can decrease the development of precursors of hematopoietic endothelium $(19,20)$ (CD34+ $\mathrm{KDR}+$ ) and prevent the emergence of hematopoietic progenitor $(\mathrm{CD} 43+)(21)$, but has no significant influence on the production of $\mathrm{CD} 34+$ cells.

To assess whether the endothelium represented by CD34+ cells was affected, p21/hESC co-cultures induced starting on D0 were subjected to FACS analyses at D4, D6, and D8. Production of CD34+CD43 - cells was not influenced, but generation of CD34+CD43 + and CD34 $-\mathrm{CD} 43+$ cells was significantly lower than in non-induced co-cultures (Fig. 6, Supplementary Fig. S2).
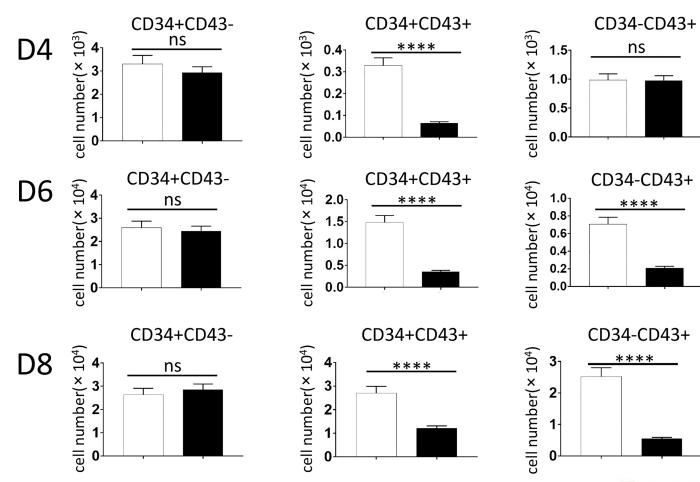

F. $\mathrm{CD} 34+\mathrm{CD} 43+$
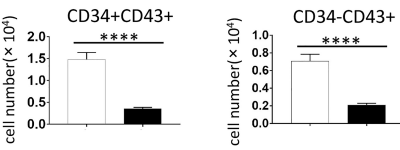

$\mathrm{CD} 34+\mathrm{CD} 43+$
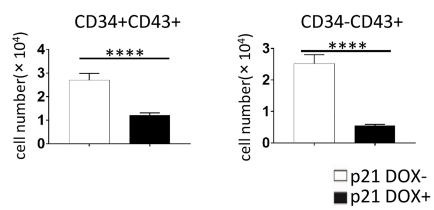

Fig. 6. Overexpression of $\mathrm{p} 21$ from D0 blocked the emergence of CD43+ cells in co-cultures with AGM-S3 cells. p21/hESC co-cultures were treated with DOX from D0, and then subjected to FACS analysis using combinations of anti-CD34/CD43 antibodies to compare non-induced co-cultures and the GFP + fraction of co-cultures at D4, D6, and D8. Production of CD34+CD43- cells was not significantly influenced, whereas production of CD34-CD43+ and CD34+CD43 + dropped significantly following induction of p21, indicating that p21 has inhibitory effects on CD43+ cells but not CD34+ cells. 

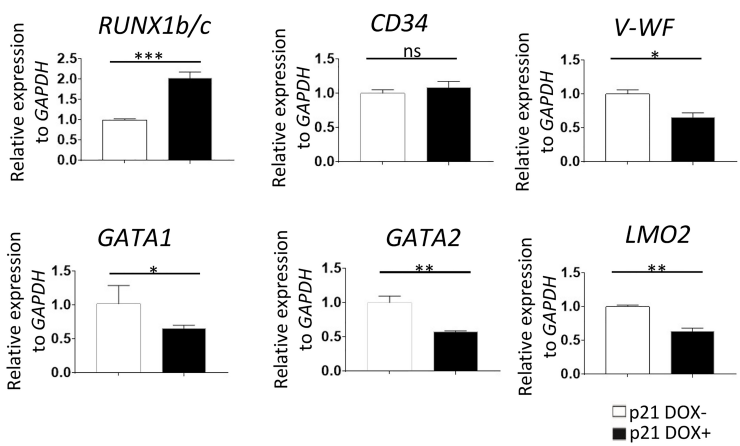

Fig. 7. Overexpression of p21 interfered with the expression of hematopoiesis-related genes in co-cultures with AGM-S3 cells. p21/ hESCs co-cultures were treated with DOX from D0. qRT-PCR analyses at D4 revealed that hematopoiesis-related genes, including GATA1, GATA2, VWF, and LOM2, were down-regulated. Expression of CD34+ was not influenced, but RUNX1b/c was up-regulated, potentially causing the inhibitory effects of p21 on hematopoiesis.

\section{Overexpression of p21 at the early stage blocks hematopoiesis by regulating the expression of hematopoiesis-related genes}

To further elucidate the molecular mechanism by which p21 blocks hematopoiesis, we performed qRT-PCR to detect changes in expression levels of hematopoietic genes. Most of them, such as GATA1, GATA2, vWF, and LOM2, were downregulated following DOX treatment (Fig. 7). The only upregulated gene was $R U N X I b / c$, which might intimately involve in the inhibitory effect of p21 on hematopoiesis. Interestingly, the expression level of $C D 34$ was not affected, indicating that production of endothelium was not significantly influenced, whereas hematopoiesis was blocked.

\section{Overexpression of p21 blocks hematopoiesis by interfering with the cell cycle}

Cell-cycle analysis of D4 co-cultures revealed that the proportion of $\mathrm{KDR}+$ cells in S phase was significantly reduced when p21 was overexpressed from D0, and that this effect could be counteracted by treatment with $0.33 \mu \mathrm{M}$ RepSox from D0 (Fig. 8A). These results indicated that down-regulation of the proportion of $\mathrm{KDR}+$ cells in $\mathrm{S}$ phase by induction of $\mathrm{p} 21$ is closely related to TGF- $\beta$ signaling, similar to the change in cell-cycle status observed in $R U N X 1 b / \mathrm{hESC}$ co-cultures treated with DOX and RepSox from D0 (Fig. 1A).

The CD34+ cells were subjected to cell-cycle analyses at D6, and the results indicated that the proportion of cells in G2-M phase was significantly downregulated when p21 was overexpressed from D0. This effect of p21 could not be counteracted by RepSox (Fig. 8B).

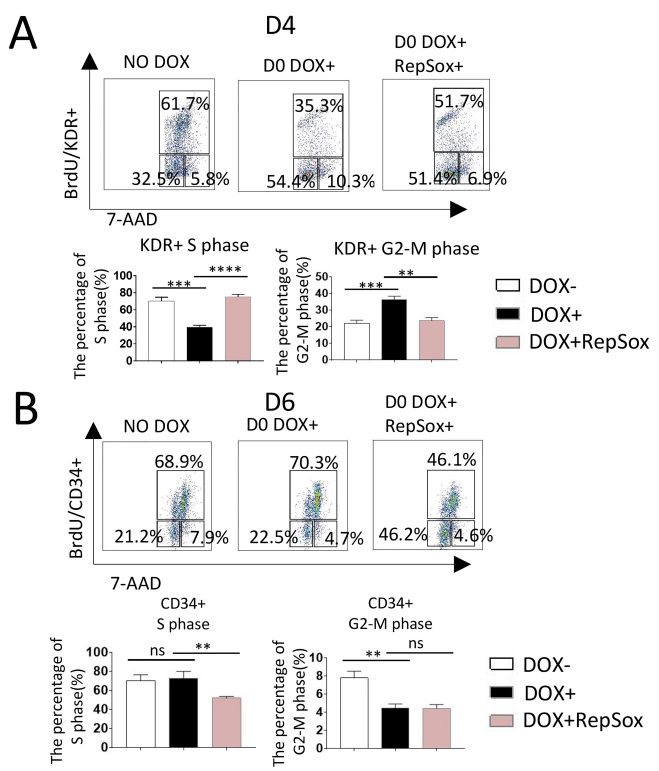

Fig. 8. Overexpression of p21 interferes with the cell-cycle status of $\mathrm{KDR}+$ and CD34+ cells in co-culture with AGM-S3 cells. In p21/hESC co-cultures with AGM-S3 cells induced from D0, cell-cycle analysis indicated that $(A)$ the proportion of KDR + cells in $S$ phase dropped significantly at D4, and this effect could be counteracted by RepSox; and that (B) the proportion of CD34+ cells in G2/M phase dropped significantly at D6, but this effect could not be counteracted by RepSox.

\section{Discussion}

Previously, we showed that RUNXIb overexpression from the early stage can block the mesoderm-hemogenic transition, and that this effect could be partially counteracted by inhibition of TGF- $\beta$ signaling (10). Subsequent research revealed that $R U N X 1 b$ overexpression also changes cell-cycle status, decreasing the proportion of S-phase cells and strongly upregulating expression of p21 (CDKN1A); this effect could also be counteracted by inhibition of TGF- $\beta$ signaling (Fig. 1). Together, these results indicate that $\mathrm{p} 21$ might be involved in the inhibitory effects of RUNXIb, which is in agreement with the negative function of p21 on cell cycle progression and hematopoiesis reported previously $(22,23)$.

Although it is an important member of the CKI family (24), the function of p21 in hematopoiesis has not yet been explored in an hESC-based in vitro system for hematopoiesis. We used the PB-Tet-on-OE vector system to establish an inducible p21/hESC line to characterize the roles of p21 (CDKN1A) in the AGM-S3 co-culture system using similar methods to those reported previously $(10,18,25)$. This approach should confer much higher accuracy than a conventional expression system to test the effects of p21 
on multiple stages, especially to uncover its roles in blockage effects of RUNXIb on hematopoiesis (10).

According to the results of FACS analysis at D12, it is obvious that $\mathrm{p} 21$ had a negative effect on the overall process of hematopoiesis, regardless of when its overexpression was induced (Fig. 3), which is in agreement with previous reports of p21 function in hematopoiesis $(23,26)$. Induction of p21 from D0 significantly decreased the production of $\mathrm{CD} 34+\mathrm{KDR}+$ cells and derivative populations such as $\mathrm{CD} 34+\mathrm{CD} 43+$ and CD34-CD43+ cells, but not other populations, at D6. This effect was weaker when induction started later and disappeared after D4. These observations indicate that p21 overexpression at an early stage (D0-D2) most strongly influenced the appearance of CD43 + cells, but not mesoderm induction (CD34-KDR + cells) or the appearance of endothelium (CD34+KDR - and $\mathrm{CD} 34+$ CD43-) (Fig. 3A). FACS analysis showed that induction at any time led to the broad blockage of hematopoiesis at $\mathrm{D} 12$, in particular decreasing the production of CD34+ $\mathrm{CD} 43+$, CD34+CD45+, and GPA +CD71 + populations. Together, these results indicate that p21 overexpression mostly acts by blocking the process of hematopoiesis, but not the precursors of hematopoiesis before CD43+ cells appearance (Fig. 3B). Colony culture assay for D0-induced co-culture at D12 revealed a significant decrease of CFU-GM, CFU-E, BFU-E, and CFU-MIX in induced co-cultures relative to non-induced cultures, indicating that D12 co-cultures had lower hematopoietic potential than those treated with DOX (Fig. 4).

To clarify the effects of p21 overexpression on hematopoiesis, we isolated $\mathrm{KDR}+$ cells from non-induced cocultures and the GFP+ fraction of D0-induced co-cultures at D2. Further hematopoietic culture revealed that induction of p21 starting on either D0 or D2 strongly blocked the appearance of CD43 + cells, but did not significantly influence the production of CD34+ cells. These results indicated that at the early stage, p21 blocks hematopoiesis at the CD43+ stage (hematopoietic progenitors) but not at the CD34 stage (endothelium) (Fig. 5). CD43 (leukosialin) expression has been used to identify early progenitors that are committed to hematopoietic development. CD43 was the marker for all emerging clonogenic progenitors that persisted on differentiating hematopoietic cells when CD45 had not be expressed, and $\mathrm{CD} 34+\mathrm{CD} 43+$ reliably defines the hematopoietic population that excludes endothelial (CD34+CD43-CD31+ $\mathrm{KDR}+$ ) (21). FACS analysis revealed that D0-induced p21/hESCs produced far fewer CD43 + cells than non-induced cultures detected at D4, especially at D6 and D8 (Fig. 6), and even at D12 (Fig. 3B). After they appeared, the inhibitory effects of p21 overexpression on CD43+ cells weakened or even disappeared when measured at D6 (Fig. 3A, panel ii). However, the inhibitory effects on the subsequent hematopoietic population were still extensive and become more severe along with the delay of p21 induction (Fig. 3B). The mechanisms underlying the inhibitory effects of p21 on hematopoiesis, and on the cell populations they target, obviously differed between the early and late stages, although the negative effects of p21 persisted throughout the overall process of hematopoiesis, consistent with previous reports (27).

Transcriptional profiling by qRT-PCR revealed that induction of p21 starting on D0 significantly downregulated many hematopoiesis-related genes, including GATA1, GATA2, vWF, and LOM2, but upregulated RUNXIb/ $c$ (which has negative effects on hematopoiesis at the early stage (10)). These changes in gene expression could explain the effects of p21 on hematopoiesis. The expression level of CD34 remained stable, consistent with the results of FACS analysis, confirming that the production of CD34+ cells was not influenced by p21 induction (Fig. 7).

Cell-cycle analysis at D4 revealed that in D0-induced $\mathrm{p} 21 / \mathrm{hESC}$ co-cultures, the proportion of $\mathrm{KDR}+$ cells in $S$ phase was significantly reduced, while the proportion in G2-M stage was significantly increased, and that this effect could be counteracted by inhibition of TGF- $\beta$ signaling (Fig. 8A). This is very similar to the effects of early-stage $R U N X 1 b$ overexpression on cell-cycle status in RUNX1b/ hESC co-cultures (Fig. 1A). These observations suggest that upregulation of $\mathrm{p} 21$ in D0-induced $R U N X 1 b / \mathrm{hESC}$ co-cultures at D4 is closely related to such a change in cell-cycle status. TGF- $\beta$ signaling can change the cell cycle status in a p21-dependent or p21-independent way, and TGF- $\beta 1$ can increase the expression of $\mathrm{p} 21(28,29)$. It can also cooperate with p21 to induce cell cycle arrest during hematopoiesis (30). According to our results, the changes in p21 expression in RUNX1b/hESC co-cultures under different culture conditions were closely related to TGF- $\beta$ signaling, whose signaling was up-regulated by RUNX1b overexpression from D0 (10).

However, these changes in the cell cycle did not influence the production of CD34+ cells in D0-induced p21/ hESC co-cultures at D4 or even at later stages, but the production of CD34+ cells could be severely blocked in D4 $R U N X 1 b / h E S C$ co-cultures. It is possible that the upregulation of $\mathrm{p} 21$ in $\mathrm{D} 4 \mathrm{RUNX} 1 \mathrm{~b} / \mathrm{hESC}$ co-cultures changed the cell-cycle status, similar to its effect in p21/ hESC co-cultures. These effects were closely related to upregulation of $\mathrm{TGF}-\beta$ signaling, which is in agreement 
with previous reports (31). However, the effects were not sufficient to block production of CD34+ cells when $R U N X 1 b$ was overexpressed from an early stage; instead, this blockage of CD34+ cells might involve other mechanisms that remain to be elucidated. Previous research showed that p21 plays either positive or negative roles during differentiation, depending on cell type and the specific stage of differentiation, so it is reasonable that $\mathrm{p} 21$ might have distinct effects on $\mathrm{KDR}+, \mathrm{CD} 34+$, and $\mathrm{CD} 43+$ cells (32).

Cell-cycle analysis at D6 revealed that D0-induced p21 could significantly decrease the proportion of CD34+ cells in G2-M phase, but not G0 or S phase; this might be related to blockage of CD43 + cells. The effect could not be counteracted by inhibition of TGF- $\beta$ signaling: in D0-induced p21/hESC co-culture at D6, RepSox significantly decreased the proportion of cells in $S$ phase, but did not affect the proportion of cells in G2-M phase (Fig. $8 \mathrm{~B})$. This observation might explain why inhibition of TGF- $\beta$ signaling could not rescue the inhibitory effects of p21 overexpression from D0 on CD43 + cells. Similarly, inhibition of TGF- $\beta$ signaling could only rescue the inhibitory effects of RUNX1b overexpression from D0 on CD34+ cells, but it did not help to recover production of CD43+ cells in D0-induced RUNX1b/hESC co-cultures at D6 or D8 (10). This might be because that the changes in cell cycle status of CD34+ cells caused by upregulation of p21 could not be counteracted by RepSox inhibition of TGF- $\beta$ signaling, so the transition from CD34+ (endothelium) to CD43+ (hematopoietic cells) was still severely blocked.

The C-terminal domain of p21 is sufficient to block processive DNA synthesis (33-35). Because p21 is usually degraded during normal $S$ phase (36), this phenomenon can be observed only when p21 is overexpressed (37). Overexpression of RUNX1b can significantly up-regulate p21 in KDR + cells, leading to a reduced proportion of these cells in $S$ phase. p21 causes G2 arrest in two ways: (a) by inhibiting CDK-activating kinase (CAK) and thus activating phosphorylation by $\operatorname{CDKs}(38,39)$; and (b) by mediating cyclin B1 degradation in the presence of DNA lesions and down-regulating early mitotic inhibitor 1 (Emil) (40), both of which will prevent G2-arrested cells from entering mitosis. p21 overexpression might prevent production of CD43 + cells from CD34+ cells primarily via such mechanisms.

Together, these results clearly demonstrate that upregulation of p21 at an early stage might explain the inhibitory effects of RUNX1b on CD43 + cells. However, this seems not to be the case with $\mathrm{CD} 34+$ cells, for which other mo- lecular or cellular mechanisms must be involved. The change in the proportion of CD34+ cells in G2-M stage in D0-induced $\mathrm{p} 21 / \mathrm{hESC}$ co-cultures might be related to the inhibitory effects on CD43 + cells, which in turn are caused by transcriptional changes in hematopoiesis-related genes and cannot be rescued by inhibition of TGF- $\beta$ signaling. The detailed relationship between the cell cycle and hematopoiesis, which are coupled through p21 and TGF- $\beta$ signaling, should be closely examined in future studies. Our results provide a novel insight into the relationship between hematopoiesis and cell-cycle status.

\section{Acknowledgments}

We thank Professor Tao Cheng from the State Key Laboratory of Experimental Hematology, CAMS \& PUMC for generously providing the $\mathrm{H} 1 \mathrm{hESC}$ line. This work was supported by awards from the CAMS Initiatives for Innovative Medicine (2016-I2M-1-018 to F. Ma and 2017-I2M3-021 to J.X. Liu), Sichuan Provincial Science and Technology Department Key R\&D projects (020YFSY0023 to B. Chen), and Chengdu Science and Technology ProjectTechnology Innovation R\&D (2018-YF05-01341-SN to B. Chen).

\section{Potential Conflict of Interest}

The authors have no conflicting financial interest.

\section{Supplementary Materials}

Supplementary data including materials and methods, two tables and two figures can be found with this article online at http://pdf.medrang.co.kr/paper/pdf/IJSC/IJSC-13s20033.pdf.

\section{References}

1. Palis J, Yoder MC. Yolk-sac hematopoiesis: the first blood cells of mouse and man. Exp Hematol 2001;29:927-936

2. Medvinsky A, Dzierzak E. Definitive hematopoiesis is autonomously initiated by the AGM region. Cell 1996;86:897906

3. Rhodes KE, Gekas C, Wang Y, Lux CT, Francis CS, Chan DN, Conway S, Orkin SH, Yoder MC, Mikkola HK. The emergence of hematopoietic stem cells is initiated in the placental vasculature in the absence of circulation. Cell Stem Cell 2008;2:252-263

4. Thomson JA, Itskovitz-Eldor J, Shapiro SS, Waknitz MA, Swiergiel JJ, Marshall VS, Jones JM. Embryonic stem cell lines derived from human blastocysts. Science 1998;282: 1145-1147

5. Ma F, Wang D, Hanada S, Ebihara Y, Kawasaki H, Zaike Y, Heike T, Nakahata T, Tsuji K. Novel method for effi- 
cient production of multipotential hematopoietic progenitors from human embryonic stem cells. Int J Hematol 2007; 85:371-379

6. Takahashi $\mathrm{K}$, Tanabe $\mathrm{K}$, Ohnuki $M$, Narita $M$, Ichisaka T, Tomoda K, Yamanaka S. Induction of pluripotent stem cells from adult human fibroblasts by defined factors. Cell 2007;131:861-872

7. Ma F, Ebihara Y, Umeda K, Sakai H, Hanada S, Zhang H, Zaike Y, Tsuchida E, Nakahata T, Nakauchi H, Tsuji $\mathrm{K}$. Generation of functional erythrocytes from human embryonic stem cell-derived definitive hematopoiesis. Proc Natl Acad Sci U S A 2008;105:13087-13092

8. Palis J. Hematopoietic stem cell-independent hematopoiesis: emergence of erythroid, megakaryocyte, and myeloid potential in the mammalian embryo. FEBS Lett 2016;590: 3965-3974

9. Han X, Liu J. Cell cycle-independent roles of p19INK4d in human terminal erythropoiesis. Chin J Cancer 2017;36: 22

10. Chen B, Teng J, Liu H, Pan X, Zhou Y, Huang S, Lai M, Bian G, Mao B, Sun W, Zhou Q, Yang S, Nakahata T, Ma F. Inducible overexpression of RUNX1b/c in human embryonic stem cells blocks early hematopoiesis from mesoderm. J Mol Cell Biol 2017;9:262-273

11. Xiong Y, Hannon GJ, Zhang H, Casso D, Kobayashi R, Beach D. p21 is a universal inhibitor of cyclin kinases. Nature 1993;366:701-704

12. Ouellet S, Vigneault F, Lessard M, Leclerc S, Drouin R, Guérin SL. Transcriptional regulation of the cyclin-dependent kinase inhibitor 1A (p21) gene by NFI in proliferating human cells. Nucleic Acids Res 2006;34:6472-6487

13. Stier S, Cheng T, Forkert R, Lutz C, Dombkowski DM, Zhang JL, Scadden DT. Ex vivo targeting of p21Cip1/Waf1 permits relative expansion of human hematopoietic stem cells. Blood 2003;102:1260-1266

14. Matsumura I, Ishikawa J, Nakajima K, Oritani $\mathrm{K}$, Tomiyama Y, Miyagawa J, Kato T, Miyazaki H, Matsuzawa Y, Kanakura Y. Thrombopoietin-induced differentiation of a human megakaryoblastic leukemia cell line, CMK, involves transcriptional activation of $\mathrm{p} 21(\mathrm{WAF} 1 / \mathrm{Cip} 1)$ by STAT5. Mol Cell Biol 1997;17:2933-2943

15. Eilken HM, Nishikawa S, Schroeder T. Continuous singlecell imaging of blood generation from haemogenic endothelium. Nature 2009;457:896-900

16. Mao B, Huang S, Lu X, Sun W, Zhou Y, Pan X, Yu J, Lai M, Chen B, Zhou Q, Mao S, Bian G, Zhou J, Nakahata T, Ma F. Early development of definitive erythroblasts from human pluripotent stem cells defined by expression of glycophorin A/CD235a, CD34, and CD36. Stem Cell Reports 2016;7:869-883

17. Chang J, Sun W, Zeng J, Xue Y, Zhang Y, Pan X, Zhou Y, Lai M, Bian G, Zhou Q, Liu J, Chen B, Guo F, Ma F. Establishment of an in vitro system based on AGM-S3 coculture for screening traditional herbal medicines that stimulate hematopoiesis. J Ethnopharmacol 2019;240:111938

18. Zhou Y, Zhang Y, Chen B, Dong Y, Zhang Y, Mao B, Pan
X, Lai M, Chen Y, Bian G, Zhou Q, Nakahata T, Zhou J, Wu M, Ma F. Overexpression of GATA2 enhances development and maintenance of human embryonic stem cellderived hematopoietic stem cell-like progenitors. Stem Cell Reports 2019;13:31-47

19. Palpant NJ, Wang Y, Hadland B, Zaunbrecher RJ, Redd M, Jones D, Pabon L, Jain R, Epstein J, Ruzzo WL, Zheng Y, Bernstein I, Margolin A, Murry CE. Chromatin and transcriptional analysis of mesoderm progenitor cells identifies HOPX as a regulator of primitive hematopoiesis. Cell Rep 2017;20:1597-1608

20. Yuan X, Braunstein EM, Ye Z, Liu CF, Chen G, Zou J, Cheng L, Brodsky RA. Generation of glycosylphosphatidylinositol anchor protein-deficient blood cells from human induced pluripotent stem cells. Stem Cells Transl Med 2013;2:819-829

21. Vodyanik MA, Thomson JA, Slukvin II. Leukosialin (CD43) defines hematopoietic progenitors in human embryonic stem cell differentiation cultures. Blood 2006;108: 2095-2105

22. Gartel AL, Radhakrishnan SK. Lost in transcription: p21 repression, mechanisms, and consequences. Cancer Res 2005;65:3980-3985

23. Cheng T, Rodrigues N, Shen H, Yang Y, Dombkowski D, Sykes M, Scadden DT. Hematopoietic stem cell quiescence maintained by p21cipl/wafl. Science 2000;287:1804-1808

24. Waga S, Hannon GJ, Beach D, Stillman B. The p21 inhibitor of cyclin-dependent kinases controls DNA replication by interaction with PCNA. Nature 1994;369:574-578

25. Sun W, Teng J, Zeng J, Xue Y, Chang J, Zhang Y, Pan X, Zhou Y, Lai M, Bian G, Zhou Q, Liu J, Chen B, Ma F. The piggyBac-based double-inducible binary vector system: a novel universal platform for studying gene functions and interactions. Plasmid 2019;105:102420

26. Xiao Y, Wang J, Song H, Zou P, Zhou D, Liu L. CD34+ cells from patients with myelodysplastic syndrome present different p21 dependent premature senescence. Leuk Res 2013;37:333-340

27. Albanese $\mathrm{P}$, Chagraoui J, Charon $M$, Cocault L, Dusanter-Fourt I, Romeo PH, Uzan G. Forced expression of p21 in GPIIb-p21 transgenic mice induces abnormalities in the proliferation of erythroid and megakaryocyte progenitors and primitive hematopoietic cells. Exp Hematol 2002; 30:1263-1272

28. Fortunel NO, Hatzfeld A, Hatzfeld JA. Transforming growth factor-beta: pleiotropic role in the regulation of hematopoiesis. Blood 2000;96:2022-2036

29. Cheng T, Shen H, Rodrigues N, Stier S, Scadden DT. Transforming growth factor beta 1 mediates cell-cycle arrest of primitive hematopoietic cells independent of p21(Cipl/Wafl) or p27(Kipl). Blood 2001;98:3643-3649

30. Ducos K, Panterne B, Fortunel N, Hatzfeld A, Monier MN, Hatzfeld J. p21(cipl) mRNA is controlled by endogenous transforming growth factor-betal in quiescent human hematopoietic stem/progenitor cells. J Cell Physiol 2000;184:8085 
31. Cordenonsi M, Dupont S, Maretto S, Insinga A, Imbriano C, Piccolo S. Links between tumor suppressors: p53 is required for TGF-beta gene responses by cooperating with Smads. Cell 2003;113:301-314

32. Dutto I, Tillhon M, Cazzalini O, Stivala LA, Prosperi E. Biology of the cell cycle inhibitor p21(CDKN1A): molecular mechanisms and relevance in chemical toxicology. Arch Toxicol 2015;89:155-178

33. Warbrick E, Lane DP, Glover DM, Cox LS. A small peptide inhibitor of DNA replication defines the site of interaction between the cyclin-dependent kinase inhibitor p21WAF1 and proliferating cell nuclear antigen. Curr Biol 1995;5:275-282

34. Chen J, Saha P, Kornbluth S, Dynlacht BD, Dutta A. Cyclin-binding motifs are essential for the function of p21CIP1. Mol Cell Biol 1996;16:4673-4682

35. Oku T, Ikeda S, Sasaki H, Fukuda K, Morioka H, Ohtsuka E, Yoshikawa H, Tsurimoto T. Functional sites of human PCNA which interact with p21 (Cipl/Wafl), DNA polymerase delta and replication factor C. Genes Cells 1998;3: 357-369
36. Gottifredi V, McKinney K, Poyurovsky MV, Prives C. Decreased p21 levels are required for efficient restart of DNA synthesis after S phase block. J Biol Chem 2004;279: 5802-5810

37. Cazzalini O, Perucca P, Riva F, Stivala LA, Bianchi L, Vannini V, Ducommun B, Prosperi E. p21CDKN1A does not interfere with loading of PCNA at DNA replication sites, but inhibits subsequent binding of DNA polymerase delta at the G1/S phase transition. Cell Cycle 2003;2:596603

38. Smits VA, Klompmaker R, Vallenius T, Rijksen G, Mäkela TP, Medema RH. p21 inhibits Thr161 phosphorylation of Cdc2 to enforce the G2 DNA damage checkpoint. J Biol Chem 2000;275:30638-30643

39. Charrier-Savournin FB, Château MT, Gire V, Sedivy J, Piette J, Dulic V. p21-Mediated nuclear retention of cyclin B1-Cdk1 in response to genotoxic stress. Mol Biol Cell 2004; 15:3965-3976

40. Gillis LD, Leidal AM, Hill R, Lee PW. p21Cip1/WAF1 mediates cyclin B1 degradation in response to DNA damage. Cell Cycle 2009;8:253-256 